\title{
Pyrogallol inhibits the growth of gastric cancer SNU-484 cells via induction of apoptosis
}

\author{
WOO HYUN PARK ${ }^{1}$, MEE NA PARK ${ }^{2}$, YONG HWAN HAN ${ }^{1}$ and SANG WOO KIM ${ }^{2}$ \\ Departments of ${ }^{1}$ Physiology, ${ }^{2}$ Internal Medicine, Medical School, Research Institute of \\ Clinical Medicine, Chonbuk National University, JeonJu 561-180, Korea
}

Received March 24, 2008; Accepted May 29, 2008

DOI: 10.3892/ijmm_00000018

\begin{abstract}
Pyrogallol (PG) is a polyphenol compound and is known to be an $\mathrm{O}_{2}{ }^{-}$generator. We evaluated the effects of PG on the growth of human gastric cancer SNU-484 cells in relation to the cell cycle and apoptosis. Dose-dependent inhibition of cell growth was observed in SNU-484 cells with an $\mathrm{IC}_{50}$ of $\sim 50 \mu \mathrm{M}$ following treatment with PG for $72 \mathrm{~h}$. DNA flow cytometric analysis indicated that treatment with PG generally did not induce the specific cell cycle phase arrest. Treatment with $50 \mu \mathrm{M}$ PG induced apoptosis $20 \%$, as evidenced by sub-G1 cells and annexin V-staining cells. Treatment with PG also induced the loss of mitochondrial membrane potential $\left(\Delta \Psi_{\mathrm{m}}\right)$ in SNU-484 cells. The intracellular reactive oxygen species (ROS) levels including $\mathrm{O}_{2}{ }^{- \text {- }}$ were significantly increased in PG-treated cells. Furthermore, the depletion of the intracellular glutathione (GSH) content was observed in cells treated with 50 or $80 \mu \mathrm{M}$ PG. In conclusion, PG inhibited the growth of human gastric cancer SNU-484 cells by inducing cell cycle arrest as well as triggering apoptosis. The changes in ROS and GSH by PG were closely related to apoptosis in SNU-484 cells.
\end{abstract}

Correspondence to: Dr Woo Hyun Park, Department of Physiology, Medical School, Chonbuk National University, JeonJu 561-180, Korea

E-mail: parkwh71@chonbuk.ac.kr

Dr Sang Woo Kim, Department of Internal Medicine, Medical School, Chonbuk National University, JeonJu 561-180, Korea E-mail: clickm@chonbuk.ac.kr

Abbreviations: PG, pyrogallol; ROS, reactive oxygen species; PARP, poly(ADP-ribose) polymerase; FBS, fetal bovine serum; MTT, 3-(4,5-dimethylthiazol-2-yl)-2,5-diphenyltetrazolium bromide; PI, propidium iodide; FITC, fluorescein isothiocyanate; DAPI, 4'-6-diamidino-2-phenylindole; $\mathrm{H}_{2}$ DCFDA, 2', 7'-dichlorodihydro-fluorescein diacetate; DHE, dihydroethidium; GSH, glutathione; CMFDA, 5-chloromethylfluorescein diacetate

Key words: pyrogallol, cell cycle, apoptosis, SNU-484, reactive oxygen species

\section{Introduction}

Pyrogallol (PG) is a polyphenol compound derived from green tea or garlic (1). The compound as an $\mathrm{O}_{2}{ }^{--}$generator has been used to investigate the role of $\mathrm{O}_{2}{ }^{\bullet-}$ in the biological system $(2,3)$. Reactive oxygen species (ROS) including $\mathrm{O}_{2}{ }^{*}$ are formed as by-products of mitochondrial respiration or oxidases such as nicotine adenine diphosphate (NADPH) oxidase, xanthine oxidase (XO) and arachidonic acid oxygenases (4). A change in the redox state of the tissue implies a change in ROS generation or metabolism. Principal metabolic pathways include superoxide dismutase (SOD), which is expressed as extracellular, intracellular and mitochondrial isoforms. These isoforms metabolize $\mathrm{O}_{2}{ }^{*-}$ to $\mathrm{H}_{2} \mathrm{O}_{2}$. Further metabolism by peroxidases that include catalase and glutathione (GSH) peroxidase yields $\mathrm{O}_{2}$ and $\mathrm{H}_{2} \mathrm{O}$ (5). Cells possess antioxidant systems to control the redox state, which is important for their survival. Excessive production of ROS gives rise to the activation of events that lead to death and survival in several types of cells (6). PG also induces $\mathrm{O}_{2}{ }^{*-}$ mediated death of several types of cell such as mesangial (7), human lymphoma (2), human glioma (8) and As4.1 juxtaglomerular cells (9).

The cell cycle in eukaryotes is regulated by cyclindependent kinases (CDKs). The cyclins, members of the cell cycle regulators, bind to and activate CDKs. Sequential formation, activation and subsequent inactivation of CDKs and cyclins are critical for control of the cell cycle (10). During the last decades it has been clear that less traditional factors as well as traditional cell cycle regulators such as nutrients, growth factors and hormones may have an important impact on cell cycle regulation. Of the former the ROS including $\mathrm{O}_{2}{ }^{--}$were commonly thought to be merely toxic to cells, leading to cell death as the ultimate consequence. Evidence is now accumulating that ROS might also play a role as signaling molecules (11), and as such they may have a role in cell cycle progression.

Gastric cancer is the second leading cause of death from cancer worldwide and in many Asian countries, such as Korea, China and Japan (12). Various novel therapeutic strategies are currently under consideration, as the clinical use of cytotoxic drugs is limited due to intrinsic or acquired resistance and toxicity. Studies of the molecular mechanisms of cytotoxic drug action have shed light on the treatment of gastric cancer, and novel agents that target specific 
intracellular pathways related to the distinctive properties of cancer cells continue to be developed.

The role of $\mathrm{O}_{2}{ }^{--}$produced by PG in gastric cancer cell death has not been evaluated. In the present study, we evaluated the effects of PG on the growth of human gastric cancer SNU-484 cells in relation to the cell cycle and apoptosis.

\section{Materials and methods}

Cell culture. The human gastric cancer SNU-484 cell line was obtained from the Korean Cell Line Bank (KCLB) and was maintained in a humidified incubator containing $5 \% \mathrm{CO}_{2}$ at $37^{\circ} \mathrm{C}$. SNU-484 cells were cultured in RPMI-1640 supplemented with $10 \%$ fetal bovine serum (FBS) and $1 \%$ penicillin-streptomycin (Gibco BRL, Grand Island, NY). Cells were routinely grown in $100-\mathrm{mm}$ plastic tissue culture dishes (Nunc, Roskilde, Denmark) and harvested with a solution of trypsin-EDTA while in a logarithmic phase of growth. Cells were maintained in these culture conditions for all experiments.

Reagents. PG was purchased from Sigma-Aldrich Chemical Co. (St. Louis, MO). PG was dissolved in $\mathrm{H}_{2} \mathrm{O}$ at $1 \times 10^{-1} \mathrm{M}$ as a stock solution. All of the stock solutions were wrapped in foil and kept at 4 or $-20^{\circ} \mathrm{C}$.

Cell growth assay. The effect of PG on the growth of SNU-484 cells were determined by measuring 3-(4,5-dimethylthiazol2-yl)-2,5-diphenyltetrazolium bromide (MTT) dye absorbance of living cells as described previously (13). In brief, cells were seeded in a 96-well microtiter plate for an MTT assay. After exposure to $0-80 \mu \mathrm{M}$ PG for $72 \mathrm{~h}, 20 \mu \mathrm{l}$ of MTT (Sigma) solution ( $2 \mathrm{mg} / \mathrm{ml}$ in PBS) was added to each well of a 96-well plate. The plate was incubated for an additional 3 or $4 \mathrm{~h}$ at $37^{\circ} \mathrm{C}$. MTT solution in medium was withdrawn by pipetting. To achieve solubilization of the formazan crystals that formed in viable cells, 100 or $200 \mu 1$ of DMSO was added to each well. The optical density of each well was measured at $570 \mathrm{~nm}$ using a microplate reader (Spectra Max 340, Molecular Devices Co, Sunnyvale, CA).

Detection of intracellular general ROS and $\mathrm{O}_{2}{ }^{*-}$ concentration. Intracellular general ROS such as $\mathrm{H}_{2} \mathrm{O}_{2}, \cdot \mathrm{OH}$ and ONOO• were detected by means of an oxidation-sensitive fluorescent probe dye, 2',7'-dichlorodihydrofluorescein diacetate ( $\mathrm{H}_{2}$ DCFDA) (Invitrogen Molecular Probes, Eugene, OR). $\mathrm{H}_{2}$ DCFDA was deacetylated intracellularly by nonspecific esterase, which was further oxidized by cellular peroxides, yielding 2,7-dichlorofluorescein (DCF), a fluorescent compound $(\mathrm{Ex} / \mathrm{Em}=495 \mathrm{~nm} / 529 \mathrm{~nm})$. DCF is poorly selective for the superoxide anion radical $\left(\mathrm{O}_{2}{ }^{-}\right)$. In contrast, dihydroethidium $(\mathrm{DHE})(\mathrm{Ex} / \mathrm{Em}=518 \mathrm{~nm} / 605 \mathrm{~nm})$ (Invitrogen Molecular Probes) is a fluorogenic probe that is highly selective for $\mathrm{O}_{2}{ }^{\bullet}$ among ROS. DHE is cell-permeable and reacts with the superoxide anion to form ethidium, which in turn intercalates in deoxyribonucleic acid, thereby exhibiting a red fluorescence. In brief, cells were incubated with the designated doses of PG for $72 \mathrm{~h}$. Cells were then washed in PBS and incubated with $20 \mu \mathrm{M} \mathrm{H}_{2}$ DCFDA or $5 \mu \mathrm{M}$
DHE at $37^{\circ} \mathrm{C}$ for $30 \mathrm{~min}$ according to the manufacturer's instructions. DCF fluorescence and red fluorescence were detected using a FACStar flow cytometer (Becton Dickinson). For each sample, 5,000 or 10,000 events were collected. ROS and $\mathrm{O}_{2} \bullet$-levels were expressed as mean fluorescence intensity (MFI), which was calculated by CellQuest software.

Cell cycle and sub-G1 analysis. Cell cycle and sub-G1 distribution were determined by the staining of DNA with propidium iodide (PI; Sigma-Aldrich) $(\mathrm{Ex} / \mathrm{Em}=488 \mathrm{~nm} / 617 \mathrm{~nm})$ as previously described (14). PI is a fluorescent biomolecule that can be used to stain DNA. In brief, $1 \times 10^{6}$ cells were incubated with the designated doses of PG for $72 \mathrm{~h}$. Cells were then washed with phosphate-buffered saline (PBS) and fixed in $70 \%$ ethanol. Cells were washed again with PBS and then incubated with PI $(10 \mu \mathrm{g} / \mathrm{ml})$ with simultaneous treatment of RNase at $37^{\circ} \mathrm{C}$ for $30 \mathrm{~min}$. The percentages of cells in different phases of the cell cycle or having sub-G1 DNA content were measured with a FACStar flow cytometer and analyzed using lysis II and CellFit software (Becton Dickinson) or ModFit software (Verity Software House, Inc., ME).

Annexin $V$-staining. Apoptosis was determined by staining cells with annexin V-fluorescein isothiocyanate (FITC) $(\mathrm{Ex} / \mathrm{Em}=488 \mathrm{~nm} / 519 \mathrm{~nm})$, since annexin $\mathrm{V}$ can be used to identify the externalization of phosphatidylserine during the progression of apoptosis and, therefore, can detect cells during early phases of apoptosis. In brief, cells were incubated with the designated doses of PG for $72 \mathrm{~h}$. Cells were washed twice with cold PBS and then resuspended in $500 \mu \mathrm{l}$ of binding buffer (10 mM HEPES/NaOH pH 7.4, $\left.140 \mathrm{mM} \mathrm{NaCl}, 2.5 \mathrm{mM} \mathrm{CaCl}_{2}\right)$ at a concentration of $1 \times 10^{6}$ cells/ml. Annexin V-FITC (5 $\mu 1$ ) (Pharmingen, San Diego, CA) was then added to the cells, which were analyzed with a FACStar flow cytometer.

Measurement of mitochondrial membrane potential $\left(\Delta \Psi_{m}\right)$. The mitochondrial membrane was monitored using the Rhodamine 123 fluorescent dye $(E x / E m=485 \mathrm{~nm} / 535 \mathrm{~nm})$, a cell-permeable cationic dye, which preferentially enters mitochondria based on the highly negative mitochondrial membrane potential $\left(\Delta \Psi_{\mathrm{m}}\right)$. Depolarization of mitochondrial membrane potential $\left(\Delta \Psi_{\mathrm{m}}\right)$ results in the loss of Rhodamine 123 from the mitochondria and a decrease in intracellular fluorescence. In brief, cells were incubated with the designated doses of PG for $72 \mathrm{~h}$. Cells were washed twice with PBS and incubated with Rhodamine $123\left(0.1 \mu \mathrm{g} / \mathrm{ml}\right.$; Sigma) at $37^{\circ} \mathrm{C}$ for $30 \mathrm{~min}$. Rhodamine 123 staining intensity was determined by flow cytometry of a FACStar flow cytometer.

Western blot analysis. Cells were incubated with the designated doses of PG for $72 \mathrm{~h}$. The cells were then washed in PBS and suspended in $5 \mathrm{Vol}$ of lysis buffer [20 $\mathrm{mM}$ HEPES (pH 7.9), 20\% glycerol, $200 \mathrm{mM} \mathrm{KCl,} 0.5 \mathrm{mM}$ EDTA, 0.5\% NP40, $0.5 \mathrm{mM}$ DTT and $1 \%$ protease inhibitor cocktail (from Sigma)]. The lysates were then collected and stored at $-20^{\circ} \mathrm{C}$ until further use. The supernatant protein concentration was determined by the Bradford method. Supernatant samples containing $40 \mu \mathrm{g}$ of total protein were 


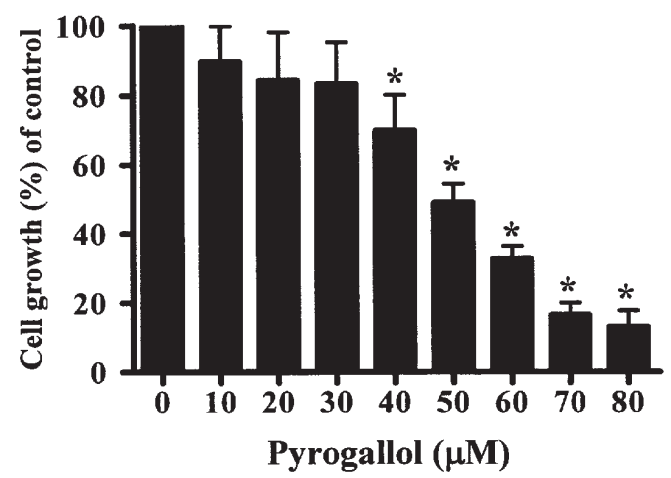

Figure 1. Effects of PG on the growth of SNU-484 cells in vitro. Exponentially growing cells were treated with the indicated concentrations of PG for $72 \mathrm{~h}$. Cell growth was determined using MTT assay. ${ }^{*} \mathrm{P}<0.05$ compared with the PG-untreated control cell group. The results represent the mean of at least two independent experiments; bar, SD.

resolved by $8,12.5$, or $15 \%$ SDS-PAGE gel depending on the target protein sizes and were transferred onto a Immobilon-P PVDF membrane (Millipore, MA) by electroblotting. The samples were then probed with anti-p53, anti-Bax, antiBcl-2, anti-caspase-3, anti-PARP and anti- $\beta$-actin (Santa Cruz Biotechnology, Santa Cruz, CA). The membranes were incubated with horseradish peroxidase-conjugated secondary antibodies. The membrane blots were developed by using the ECL kit (Amersham, Arlington Heights, IL).

Detection of intracellular glutathione (GSH). Cellular GSH levels were analyzed using 5-chloromethylfluorescein diacetate (CMFDA, Molecular Probes) $(\mathrm{Ex} / \mathrm{Em}=522 \mathrm{~nm} /$ $595 \mathrm{~nm}$ ). CMFDA is a useful, membrane-permeable dye for determining levels of intracellular glutathione (15). In brief, cells were incubated with PG for $72 \mathrm{~h}$. Cells were then washed with PBS and incubated with $5 \mu \mathrm{M} \mathrm{CMFDA}$ at $37^{\circ} \mathrm{C}$ for $30 \mathrm{~min}$ according to the manufacturer's instructions. Cytoplasmic esterases convert nonfluorescent CMFDA to fluorescent 5-chloromethylfluorescein, which can then react with the glutathione. CMF fluorescence staining intensity was determined using a FACStar flow cytometer and calculated by CellQuest software. For each sample, 5,000 or 10,000 events were collected.

Statistical analysis. Microsoft Excel or Instat software (GraphPad Prism4, San Diego, CA) was used to analyze the data. The Student's t-test or one-way analysis of variance (ANOVA) was used for parametric data. Statistical significance was defined as $\mathrm{p}<0.05$.

\section{Results}

Effects of $P G$ on the growth of SNU-484 cells in vitro. We examined the effect of PG on the growth of SNU-484 cells by an MTT assay. Dose-dependent inhibition of cell growth was observed in SNU-484 cells with an $\mathrm{IC}_{50}$ of $\sim 50 \mu \mathrm{M}$ following treatment with PG for $72 \mathrm{~h}$ (Fig. 1). The cell growth was completely inhibited at $80 \mu \mathrm{M}$ of PG (Fig. 1).

Effects of PG on cell cycle distribution in SNU-484 cells. We examined the effect of PG on the cell cycle in SNU-484

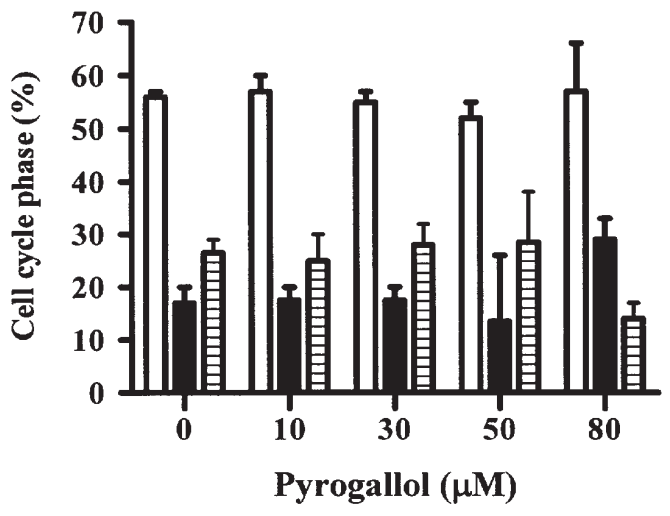

Figure 2. Effects of PG on the cell cycle distribution in SNU-484 cells. Exponentially growing cells were treated with the indicated concentrations of PG for $72 \mathrm{~h}$. The changes in cell cycle phase distribution were assessed by DNA flow cytometric analysis. The results represent the mean of at least two independent experiments; bar, SD.

cells. As shown in Fig. 2, DNA flow cytometric analysis indicated that treatment with PG generally did not induce the specific cell cycle phase arrest at $72 \mathrm{~h}$.

Effects of $P G$ on apoptosis and mitochondrial membrane potential $\left(\Delta \Psi_{m}\right)$ in SNU-484 cells. Next, we determined whether PG induces apoptosis in SNU-484 cells. As shown in Fig. 3A, treatment with 50-80 $\mu \mathrm{M}$ PG increased the number of sub-G1 cells at $72 \mathrm{~h}$. The percentage of sub-G1 SNU-484 cells was elevated to $\sim 25 \%$ for $72 \mathrm{~h}$ following treatment with $80 \mu \mathrm{M}$ PG (Fig. 3A). To further confirm and evaluate the induction of apoptosis, we stained SNU-484 cells with annexin V. Similar to the percentages of sub-G1 phase cells assessed by flow cytometry, the proportion of annexin Vstained cells in the PG-treated cells was markedly increased in a dose-dependent manner (Fig. 3B), which confirms that PG-induced SNU-484 cell death occurred via apoptosis. In addition, treatment with 50-80 $\mu \mathrm{M}$ PG significantly induced the loss of mitochondrial membrane potential $\left(\Delta \Psi_{\mathrm{m}}\right)$ in SNU-484 cells for $72 \mathrm{~h}$ (Fig. 3C).

Examination of Bcl-2 and Bax regulation during the PGinduced apoptosis revealed that Bcl-2 protein was decreased except for treatment with the dose of $5 \mu \mathrm{M}$ PG (Fig. 3D). Bax was also decreased except for treatment with the dose of $5 \mu \mathrm{M}$ PG (Fig. 3D). The expression of $\mathrm{Bcl} 2$ and $\mathrm{Bax}$ proteins in $80 \mu \mathrm{M}$ PG-treated cells was not determined due to the degradation of total proteins. In addition, p53 protein, known to be related to apoptosis, was not altered at any concentration of PG (Fig. 3D). Next, we examined whether caspase- 3 was activated during the induction of apoptosis by PG. The level of procaspase-3 (32 kDa precursor) was significantly reduced in $50 \mu \mathrm{M}$ PG-treated cells compared with the level of the control cells (Fig. 3E), which suggests that the activation of caspase- 3 occurred in $50 \mu \mathrm{M}$ PG-treated cells. Since poly(ADP-ribose) polymerase (PARP) protein is known to be a major substrate for executed caspases and a hallmark of apoptosis, Western blot analysis of PARP expression was performed. The data showed that the intact $116 \mathrm{kDa}$ PARP had completely disappeared in $50 \mu \mathrm{M}$ PGtreated SNU-484 cells, and the cleavage form of PARP had appeared in 30 or $50 \mu \mathrm{M}$ PG-treated SNU-484 cells (Fig. 3E). 
A

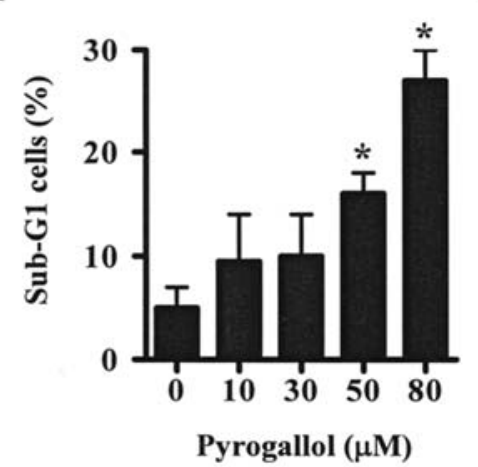

D

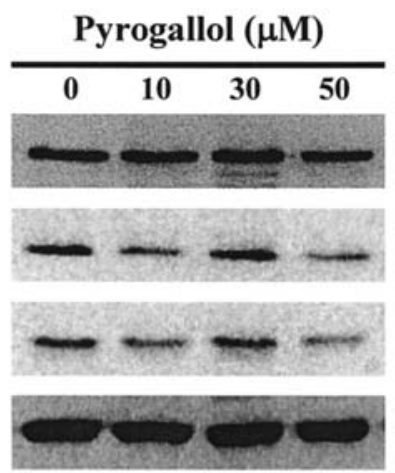

B

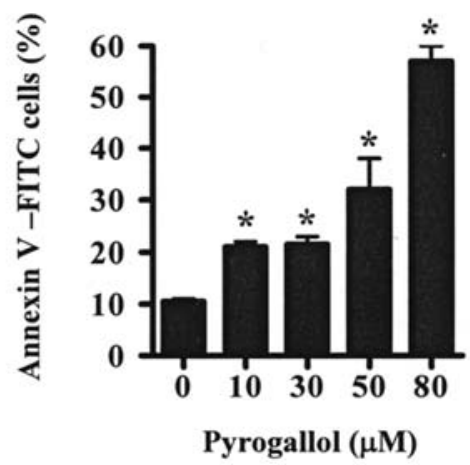

C

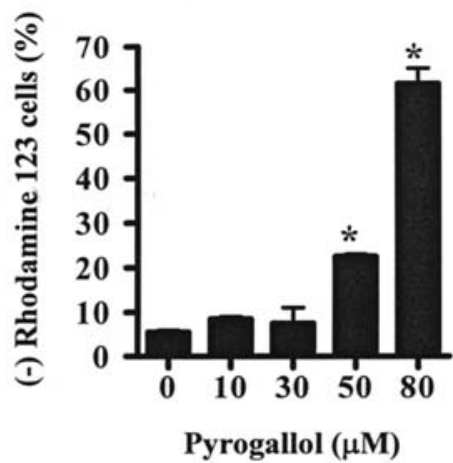

$\mathbf{E}$
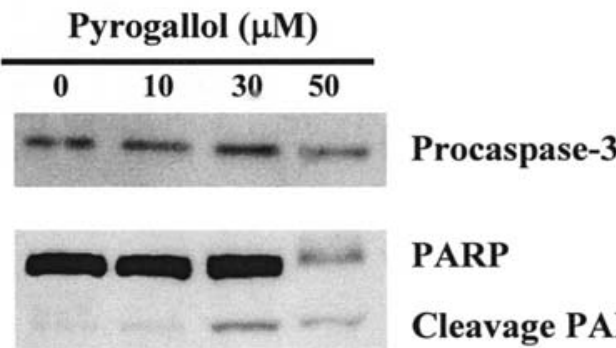

PARP

Cleavage PARP

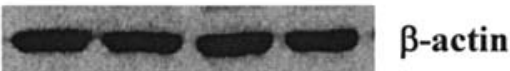

Figure 3. Effects of PG on apoptosis and mitochondrial membrane potential $\left(\Delta \Psi_{\mathrm{m}}\right)$ in SNU-484 cells. Exponentially growing cells were treated with the indicated concentrations of PG for $72 \mathrm{~h}$. (A) The percentage of sub-G1 cells in PG-treated cells. (B) The percentage of annexin V-positive cells in PG-treated cells. (C) The percentage of Rhodamine 123-negative [mitochondrial membrane potential $\left(\Delta \Psi_{\mathrm{m}}\right)$ loss] cells in PG-treated cells. (D) Aliquots of $40 \mu \mathrm{g}$ of protein extracts were resolved by $12.5 \%$ SDS-PAGE gel, transferred onto a PVDF membrane, and immunoblotted with the indicated antibodies, p53, Bax, Bcl-2 and B-actin. (E) Western blot analysis of procaspase-3, PARP and B-actin are shown. ${ }^{*}<0.05$ compared with the PG-untreated control cell group.

Effects of PG on intracellular ROS and GSH content in $S N U-484$ cells. To assess the production of the intracellular general ROS in PG-treated SNU-484 cells, we used $\mathrm{H}_{2}$ DCFDA fluorescent dye. As shown in Fig. 4A, the intracellular ROS levels were significantly increased in SNU-484 cells treated with 10-80 $\mu \mathrm{M}$ PG for $72 \mathrm{~h}$ (Fig. 4A). In addition, red fluorescence derived from DHE, which reflected $\mathrm{O}_{2}{ }^{\bullet}$ accumulation, was significantly increased in SNU-484 cells treated with 30-80 $\mu \mathrm{M}$ PG for $72 \mathrm{~h}$ (Fig. 4B).

Cellular GSH has been shown to be crucial in regulating cell proliferation, cell cycle progression, and apoptosis (16). Therefore, we analyzed the changes in GSH levels in SNU-484 cells using CMF fluorescence. As shown in Fig. 4C, the depletion of the intracellular GSH content was observed in cells treated with 50 or $80 \mu \mathrm{M}$ PG. However, the levels of GSH content were significantly increased in PG-treated SNU-484 cells (Fig. 4D). Significantly, the GSH content in $80 \mu \mathrm{M}$ PG-treated cells was not significantly altered (Fig. 4D).

\section{Discussion}

In the present study, we investigated the effects of PG on the growth of human gastric cancer SNU-484 cells in relation to the cell cycle arrest and apoptosis. Dose-dependent inhibition of cell growth was observed in SNU-484 cells with an $\mathrm{IC}_{50}$ of $\sim 50 \mu \mathrm{M}$ following treatment with $\mathrm{PG}$ for $72 \mathrm{~h}$. To explain the mechanism of cell growth inhibition by PG in relation to cell cycle change, we conducted cell cycle analysis in PG-treated cells. Treatment with PG generally did not induce specific cell cycle phase arrest at $72 \mathrm{~h}$. In fact, treatment with $50 \mu \mathrm{M}$ PG inhibited the growth of SNU-484 cells by $\sim 50 \%$, but slightly induced cell death by $\sim 20 \%$ in view of sub-G1 cells and annexin $\mathrm{V}$-stained cells. Therefore, PG presumably induced arrest during all phases of the cell cycle. Nonspecific cell cycle arrest can be considered as a pathway to suppress the growth of SNU-484 cells. We also observed that PG induces a G2 phase arrest in As4.1 juxtaglomerular cells (17) and also induces the nonspecific cell cycle arrest in HeLa cells (18). These results suggest that the specificity of cell cycle arrest by PG depends on differences in cell types.

According to our results, treatment with $\mathrm{PG}$ induced apoptosis in SNU-484 cells. To gain insight into the molecular mechanism involved in apoptosis caused by PG, expression of the apoptosis-related proteins and changes in mitochondrial transmembrane potential $\left(\Delta \Psi_{\mathrm{m}}\right)$ were assessed in SNU-484 cells. We predicted that the Bax to Bcl-2 ratio would be increased, since many apoptotic agents increase Bax protein and/or decrease $\mathrm{Bcl}-2$ protein during the apoptotic process in their target cells. However, the expression patterns of $\mathrm{Bcl}-2$ and Bax were similar in the different PG-treated SNU-484 cells. In particular, SNU-484 cells treated with $50 \mu \mathrm{M}$ PG did not up-regulate the proapoptotic protein Bax. These data suggest that Bcl-2 as well as Bax were not tightly involved in the induction of 
A

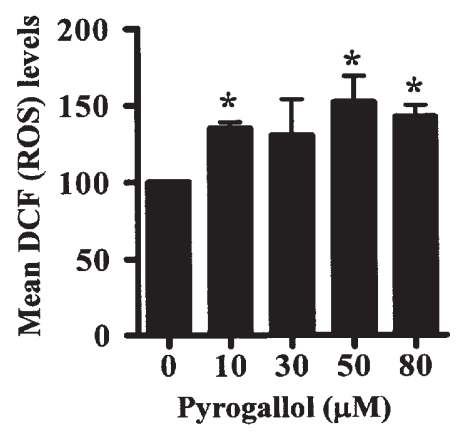

C

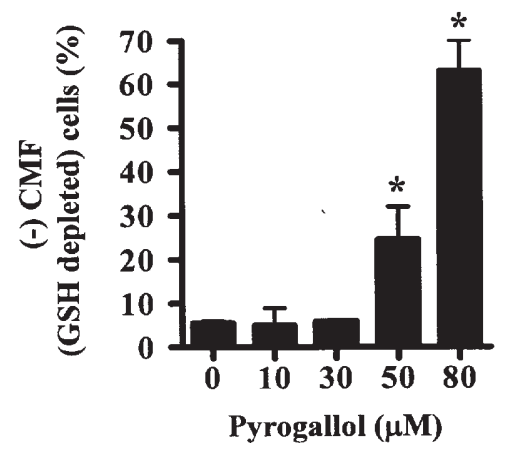

B

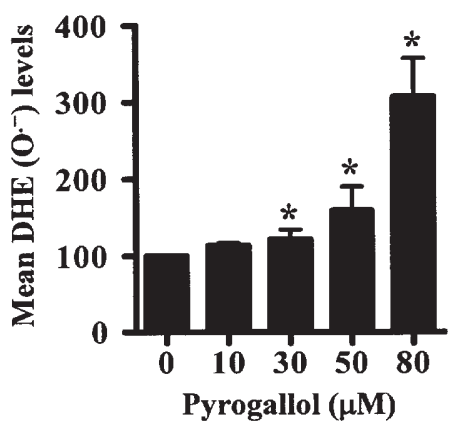

D

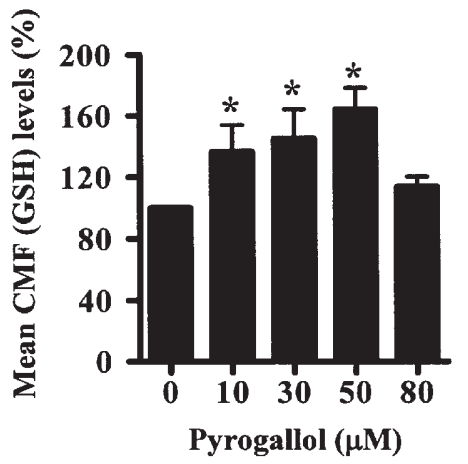

Figure 4. Effects of PG on intracellular ROS and GSH content in SNU-484 cells. Exponentially growing cells were treated with the indicated concentrations of PG for $72 \mathrm{~h}$. (A) The intracellular ROS levels were determined by a FACStar flow cytometer and the levels of mean DCF fluorescence (general ROS) in PG-treated cells are shown (B) The levels of mean DHE fluorescence $\left(\mathrm{O}_{2}{ }^{-}\right)$in PG-treated cells. (C) The intracellular GSH levels were determined by a FACStar flow cytometer as described in Materials and methods and the percentage of CMF negative (GSH-depleted) cells in PG-treated cells are shown. (D) The levels of mean CMF (GSH content) in PG-treated cells. ${ }^{*} \mathrm{P}<0.05$ compared with the PG-untreated control cell group.

apoptosis by PG. P53 induces cell cycle arrest or apoptosis in response to DNA damage and regulates Bax and Bcl-2 protein expression (19). In our experiment, the expression of p53 protein was not altered at any concentration of $\mathrm{PG}$, implying that the changes in Bax or Bcl-2 proteins were not dependent on the p53 protein level, and apoptosis triggered by PG was also not p53-dependent. It is known that the collapse of mitochondrial membrane potential $\left(\Delta \Psi_{\mathrm{m}}\right)$ occurs during apoptosis (20). Correspondingly, treatment with 50 or $80 \mu \mathrm{M}$ PG induced the loss of mitochondrial membrane potential $\left(\Delta \Psi_{\mathrm{m}}\right)$ in SNU-484 cells. Notably there were similar numbers of annexin $\mathrm{V}$-positive-stained and Rhodamine 123 negative-stained cells in 50 or $80 \mu \mathrm{M}$ PG-treated SNU-484 cells, suggesting that apoptosis by PG is tightly related to or dependent on the loss of mitochondrial membrane potential $\left(\Delta \Psi_{\mathrm{m}}\right)$.

Cytochrome $\mathrm{c}$ in cytosol forms an apoptosome that is composed of Aaf-1 and procaspase-9, resulting in activation of caspase-9. Caspase-9 activates the effector procaspases, including procaspase-3, to process apoptosis (21). Correspondingly, caspase- 3 was activated by $50 \mu \mathrm{M}$ PG, and PARP protein was degraded in 30 or $50 \mu \mathrm{M}$ PG-treated SNU-484 cells. To note, $30 \mu \mathrm{M}$ PG-treated SNU-484 cells did not show activation of caspase-3, as indirectly evidenced by lack of disappearance of procaspase-3 protein, but showed the cleavage form of PARP. This finding suggests that other executor caspases such as caspase- 6 or caspase- 7 are additionally required for the full induction of apoptosis by PG.
PG can disturb the natural oxidation and reduction equilibrium in cells. Increased patterns in $\mathrm{O}_{2}{ }^{\bullet-}$ levels by PG were reported in pheochromocytoma PC12 cells (3), neuroblastoma SH-SY5Y cells (22), lung cancer Calu-6 cells (23) and juxtaglomerular As4.1 cells (9). These findings suggest that the apoptotic effects of PG are generally correlated with changes in intracellular $\mathrm{O}_{2} \bullet^{-}$levels. Likewise, the intracellular ROS levels including $\mathrm{O}_{2}{ }^{-}$were significantly increased in SNU-484 cells treated with PG for $72 \mathrm{~h}$, verifying that $\mathrm{PG}$ as a polyphenol compound is an $\mathrm{O}_{2}$. generator (2,3). GSH, a main cell non-protein antioxidant, is able to clear away the $\mathrm{O}_{2}{ }^{-}$and provide electrons for enzymes such as glutathione peroxidase, which reduce $\mathrm{H}_{2} \mathrm{O}_{2}$ to $\mathrm{H}_{2} \mathrm{O}$ (24). It has been reported that the intracellular GSH content has a decisive effect on anticancer drug-induced apoptosis, indicating that apoptotic effects are inversely proportional to GSH content (25). Likewise, our results demonstrated that treatment with 50 or $80 \mu \mathrm{M}$ PG increased the number of GSH-depleted cells in SNU-484 cells. However, the intracellular GSH content was increased in 10-50 $\mu \mathrm{M}$ PG-treated SNU-484 cells. It is possible that SNU-484 cells increased the GSH content to compensate for the increased ROS levels by PG. In the case of $80 \mu \mathrm{M}$ PG-treated SNU-484 cells, the strongly increased ROS levels presumably caused vital damages to the GSH redox system, consequently resulting in GSH deletion and cell death in SNU-484 cells. These results verify that the intracellular GSH levels as well as ROS levels are tightly related to PG-induced cell death. 
In conclusion, $\mathrm{PG}$ inhibited the growth of human gastric cancer SNU-484 cells via inducing cell cycle arrest as well as triggering apoptosis. The changes in ROS and GSH by PG were closely related to apoptosis in SNU-484 cells. Our results suggest the possibility that PG is a candidate agent for the treatment of gastric cancer patients.

\section{Acknowledgements}

This research was supported by the Korean Research Foundation Grant funded by the Korean Government (MOEHRD, Basic Research Promotion Fund) (KRF-2007331-E00064).

\section{References}

1. Kinjo J, Nagao T, Tanaka T, et al: Activity-guided fractionation of green tea extract with antiproliferative activity against human stomach cancer cells. Biol Pharm Bull 25: 1238-1240, 2002.

2. Saeki K, Hayakawa S, Isemura M and Miyase T: Importance of a pyrogallol-type structure in catechin compounds for apoptosisinducing activity. Phytochemistry 53: 391-394, 2000.

3. Yamada J, Yoshimura S, Yamakawa $\mathrm{H}$, et al: Cell permeable ROS scavengers, Tiron and Tempol, rescue PC12 cell death caused by pyrogallol or hypoxia/reoxygenation. Neurosci Res 45: $1-8,2003$.

4. Zorov DB, Juhaszova M and Sollott SJ: Mitochondrial ROSinduced ROS release: an update and review. Biochim Biophys Acta 1757: 509-517, 2006.

5. Wilcox CS: Reactive oxygen species: roles in blood pressure and kidney function. Curr Hypertens Rep 4: 160-166, 2002.

6. Simon HU, Haj-Yehia A and Levi-Schaffer F: Role of reactive oxygen species (ROS) in apoptosis induction. Apoptosis 5: 415-418, 2000.

7. Moreno-Manzano V, Ishikawa Y, Lucio-Cazana J and Kitamura M: Selective involvement of superoxide anion, but not downstream compounds hydrogen peroxide and peroxynitrite, in tumor necrosis factor-alpha-induced apoptosis of rat mesangial cells. J Biol Chem 275: 12684-12691, 2000.

8. Sawada M, Nakashima S, Kiyono T, et al: p53 regulates ceramide formation by neutral sphingomyelinase through reactive oxygen species in human glioma cells. Oncogene 20: 1368-1378, 2001.

9. Park WH, Han YW, Kim SH and Kim SZ: A superoxide anion generator, pyrogallol induces apoptosis in As4.1 cells through the depletion of intracellular GSH content. Mutat Res 619: 81-92, 2007.
10. Kastan MB and Bartek J: Cell-cycle checkpoints and cancer. Nature 432: 316-323, 2004.

11. Boonstra J and Post JA: Molecular events associated with reactive oxygen species and cell cycle progression in mammalian cells. Gene 337: 1-13, 2004

12. Crew KD and Neugut AI: Epidemiology of gastric cancer. World J Gastroenterol 12: 354-362, 2006.

13. Park WH, Seol JG, Kim ES, et al: Arsenic trioxide-mediated growth inhibition in MC/CAR myeloma cells via cell cycle arrest in association with induction of cyclin-dependent kinase inhibitor, p21, and apoptosis. Cancer Res 60: 3065-3071, 2000.

14. Han YH, Kim SZ, Kim SH and Park WH: Arsenic trioxide inhibits growth of As4.1 juxtaglomerular cells via cell cycle arrest and caspase-independent apoptosis. Am J Physiol Renal Physiol 293: F511-F520, 2007.

15. Hedley DW and Chow S: Evaluation of methods for measuring cellular glutathione content using flow cytometry. Cytometry 15: 349-358, 1994.

16. Poot M, Teubert H, Rabinovitch PS and Kavanagh TJ: De novo synthesis of glutathione is required for both entry into and progression through the cell cycle. J Cell Physiol 163: 555-560, 1995.

17. Park WH, Han YH, Kim SH and Kim SZ: Pyrogallol, ROS generator inhibits As4.1 juxtaglomerular cells via cell cycle arrest of G2 phase and apoptosis. Toxicology 235: 130-139, 2007.

18. Kim SW, Han YW, Lee ST, et al: A superoxide anion generator, pyrogallol, inhibits the growth of HeLa cells via cell cycle arrest and apoptosis. Mol Carcinog 47: 114-125, 2007.

19. Coutts AS and La Thangue N: The p53 response during DNA damage: impact of transcriptional cofactors. Biochem Soc Symp 181-189, 2006.

20. Yang J, Liu X, Bhalla K, et al: Prevention of apoptosis by Bcl-2: release of cytochrome $\mathrm{c}$ from mitochondria blocked. Science 275: 1129-1132, 1997.

21. Cohen GM: Caspases: the executioners of apoptosis. Biochem J 326: 1-16, 1997.

22. Poulose SM, Harris ED and Patil BS: Citrus limonoids induce apoptosis in human neuroblastoma cells and have radical scavenging activity. J Nutr 135: 870-877, 2005.

23. Han YH, Kim SZ, Kim SH and Park WH: Apoptosis in pyrogallol-treated Calu- 6 cells is correlated with the changes of intracellular GSH levels rather than ROS levels. Lung Cancer 59: 301-314, 2008.

24. Rhee SG, Yang KS, Kang SW, Woo HA and Chang TS: Controlled elimination of intracellular $\mathrm{H}(2) \mathrm{O}(2)$ : regulation of peroxiredoxin, catalase, and glutathione peroxidase via posttranslational modification. Antioxid Redox Signal 7: 619-626, 2005.

25. Estrela JM, Ortega A and Obrador E: Glutathione in cancer biology and therapy. Crit Rev Clin Lab Sci 43: 143-181, 2006. 